\title{
The Surviving Sepsis Campaign Bundle: 2018 update
}

\author{
Mitchell M. Levy ${ }^{1 *}$, Laura E. Evans ${ }^{2}$ and Andrew Rhodes ${ }^{3}$
}

๑) 2018 SCCM and ESICM

\section{Introduction}

The "sepsis bundle" has been central to the implementation of the Surviving Sepsis Campaign (SSC) from the first publication of its evidence-based guidelines in 2004 through subsequent editions [1-6]. Developed separately from the guidelines publication by the SSC, the bundles have been the cornerstone of sepsis quality improvement since 2005 [7-11]. As noted when they were introduced, the bundle elements were designed to be updated as indicated by new evidence and have evolved accordingly. In response to the publication of "Surviving Sepsis Campaign: International Guidelines for Management of Sepsis and Septic Shock: 2016" [12, 13], a revised "hour-1 bundle" has been developed and is presented below (Fig. 1).

The compelling nature of the evidence in the literature, which has demonstrated an association between compliance with bundles and improved survival in patients with sepsis and septic shock, led to the adoption of the SSC measures by the National Quality Forum (NQF) and subsequently both by the New York State (NYS) Department of Health [14] and the Centers for Medicare and Medicaid Services (CMS) [15] in the USA for mandated public reporting. The important relationship between the bundles and survival was confirmed in a publication from this NYS initiative [16].

Paramount in the management of patients with sepsis is the concept that sepsis is a medical emergency. As with polytrauma, acute myocardial infarction, and stroke, early identification and appropriate immediate management in the initial hours after development of sepsis

\footnotetext{
*Correspondence: mitchell_levy@brown.edu

${ }^{1}$ Department of Medicine, Division of Pulmonary/Critical Care Medicine,

Alpert Medical School at Brown University, Providence, RI, USA

Full author information is available at the end of the article

This article is being simultaneously published in Critical Care Medicine

(https://doi.org/10.1097/CCM.0000000000003119) and Intensive Care Medicine.
}

improves outcomes $[7-11,14,16-21]$. The guidelines state that these patients need urgent assessment and treatment, including initial fluid resuscitation while pursuing source control, obtaining further laboratory results, and attaining more precise measurements of hemodynamic status. A guiding principle is that these complex patients need a detailed initial assessment and then ongoing re-evaluation of their response to treatment. The elements of the 2018 bundle, intended to be initiated within the first hour, are listed in Table 1 and presented in the following. Consistent with previous iterations of the SSC sepsis bundles, "time zero" or "time of presentation" is defined as the time of triage in the emergency department or, if referred from another care location, from the earliest chart annotation consistent with all elements of sepsis (formerly severe sepsis) or septic shock ascertained through chart review. Because this new bundle is based on the 2016 Guidelines publication, the guidelines themselves should be referred to for further discussion and evidence related to each element and to sepsis management as a whole.

\section{Hour-1 bundle}

The most important change in the revision of the SSC bundles is that the 3-h and 6-h bundles have been combined into a single "hour-1 bundle" with the explicit intention of beginning resuscitation and management immediately. We believe this reflects the clinical reality at the bedside of these seriously ill patients with sepsis and septic shock - that clinicians begin treatment immediately, especially in patients with hypotension, rather than waiting or extending resuscitation measures over a longer period. More than $1 \mathrm{~h}$ may be required for resuscitation to be completed, but initiation of resuscitation and treatment, such as obtaining blood for measuring lactate and blood cultures, administration of fluids and antibiotics, and in the case of life-threatening hypotension, initiation of vasopressor therapy, are all begun immediately.

\section{实


- Measure lactate level. Remeasure if initial lactate is $>2 \mathrm{mmol} / \mathrm{L}$.

- Obtain blood cultures prior to administration of antibiotics.

- Administer broad-spectrum antibiotics.

- Begin rapid administration of $30 \mathrm{ml} / \mathrm{kg}$ crystalloid for hypotension or lactate $\geq 4 \mathrm{mmol} / \mathrm{L}$.

- Apply vasopressors if patient is hypotensive during or after fluid resuscitation to maintain MAP $\geq 65 \mathrm{~mm} \mathrm{Hg}$.

* "Time zero" or "time of presentation" is defined as the time of triage in the Emergency Department or, if presenting from another care venue, from the earliest chart annotation consistent with all elements of sepsis (formerly severe sepsis) or septic shock ascertained through chart review.

Fig. 1 Hour-1 Surviving Sepsis Campaign Bundle of Care

Table 1 Bundle elements with strength of recommendations and under-pinning quality of evidence [12, 13]

\begin{tabular}{|c|c|}
\hline Bundle element & Grade of recommendation and level of evidence \\
\hline Measure lactate level. Re-measure if initial lactate is $>2 \mathrm{mmol} / \mathrm{L}$ & Weak recommendation, low quality of evidence \\
\hline Obtain blood cultures prior to administration of antibiotics & Best practice statement \\
\hline Administer broad-spectrum antibiotics & Strong recommendation, moderate quality of evidence \\
\hline Rapidly administer $30 \mathrm{ml} / \mathrm{kg}$ crystalloid for hypotension or lactate $\geq 4 \mathrm{mmol} / \mathrm{L}$ & Strong recommendation, low quality of evidence \\
\hline $\begin{array}{l}\text { Apply vasopressors if patient is hypotensive during or after fluid resuscitation to maintain } \\
\text { MAP } \geq 65 \mathrm{~mm} \mathrm{Hg}\end{array}$ & Strong recommendation, moderate quality of evidence \\
\hline
\end{tabular}

It is also important to note that there are no published studies that have evaluated the efficacy in important subgroups, including burns and immunocompromised patients. This knowledge gap needs to be addressed in future studies specifically targeting these subgroups. The elements included in the revised bundle are taken from the Surviving Sepsis Campaign Guidelines, and the level of evidence in support of each element can be seen in Table $1[12,13]$. We believe the new bundle is an accurate reflection of actual clinical care.

\section{Measure lactate level}

While serum lactate is not a direct measure of tissue perfusion [22], it can serve as a surrogate, as increases may represent tissue hypoxia, accelerated aerobic glycolysis driven by excess beta-adrenergic stimulation, or other causes associated with worse outcomes [23]. Randomized controlled trials have demonstrated a significant reduction in mortality with lactate-guided resuscitation [24-28].

If initial lactate is elevated ( $>2 \mathrm{mmol} / \mathrm{L}$ ), it should be remeasured within $2-4 \mathrm{~h}$ to guide resuscitation to normalize lactate in patients with elevated lactate levels as a marker of tissue hypoperfusion [24].

\section{Obtain blood cultures prior to antibiotics}

Sterilization of cultures can occur within minutes of the first dose of an appropriate antimicrobial [29, 30], so cultures must be obtained before antibiotic administration to optimize the identification of pathogens and improve outcomes [31, 32]. Appropriate blood cultures include at least two sets (aerobic and anaerobic). Administration of appropriate antibiotic therapy should not be delayed in order to obtain blood cultures.

\section{Administer broad-spectrum antibiotics}

Empiric broad-spectrum therapy with one or more intravenous antimicrobials to cover all likely pathogens should be started immediately [21] for patients presenting with sepsis or septic shock. Empiric antimicrobial therapy should be narrowed once pathogen identification and sensitivities are established, or discontinued if a decision is made that the patient does not have infection. The link between early administration of antibiotics for suspected infection and antibiotic stewardship remains an essential aspect of high-quality sepsis management. If infection is subsequently proven not to exist, then antimicrobials should be discontinued. 


\section{Administer intravenous fluid}

Early effective fluid resuscitation is crucial for the stabilization of sepsis-induced tissue hypoperfusion or septic shock. Given the urgent nature of this medical emergency, initial fluid resuscitation should begin immediately upon recognizing a patient with sepsis and/or hypotension and elevated lactate, and completed within $3 \mathrm{~h}$ of recognition. The guidelines recommend this should comprise a minimum of $30 \mathrm{ml} / \mathrm{kg}$ of intravenous crystalloid fluid. Although little literature includes controlled data to support this volume, recent interventional studies have described this as usual practice in the early stages of resuscitation, and observational evidence is supportive $[7,8]$. The absence of any clear benefit following the administration of colloid compared with crystalloid solutions in the combined subgroups of sepsis, in conjunction with the expense of albumin, supports a strong recommendation for the use of crystalloid solutions in the initial resuscitation of patients with sepsis and septic shock. Because some evidence indicates that a sustained positive fluid balance during ICU stay is harmful [33-37], fluid administration beyond initial resuscitation requires careful assessment of the likelihood that the patient remains fluid responsive.

\section{Apply vasopressors}

Urgent restoration of an adequate perfusion pressure to the vital organs is a key part of resuscitation. This should not be delayed. If blood pressure is not restored after initial fluid resuscitation, then vasopressors should be commenced within the first hour to achieve mean arterial pressure (MAP) of $\geq 65 \mathrm{~mm} \mathrm{Hg}$. The physiologic effects of vasopressors and combined inotrope/vasopressor selection in septic shock are outlined in a large number of literature reviews [38-47].

\section{Summary}

Previous iterations of the sepsis bundle were introduced as a means of providing education and improvement related to sepsis management. The literature supports the use of sepsis bundles for improving outcomes in patients with sepsis and septic shock. This new sepsis "hour-1 bundle," based on the 2016 guidelines, should be introduced to emergency department, floor, and ICU staff as the next iteration of ever-improving tools in the care of patients with sepsis and septic shock as we all work to lessen the global burden of sepsis.

\footnotetext{
Author details

${ }^{1}$ Department of Medicine, Division of Pulmonary/Critical Care Medicine, Alpert Medical School at Brown University, Providence, RI, USA. ${ }^{2}$ New York University School of Medicine, New York, NY, USA. ${ }^{3}$ St. George's University Hospitals NHS Foundation Trust and St George's University of London, London, UK.
}

\section{Acknowledgements}

The authors gratefully acknowledge Deb McBride and Lori Harmon for their invaluable assistance with manuscript preparation and editing (DM) and overall support for this work (DM and LH).

\section{Compliance with ethical standards}

\section{Conflicts of interest}

Dr. Levy is a Member of the Surviving Sepsis Campaign Executive Committee and is a Surviving Sepsis Campaign Guidelines Author. Dr. Evans is a Member of the Surviving Sepsis Campaign Steering Committee and is a Surviving Sepsis Campaign Guidelines Co-Chair. Dr. Rhodes is a Member of the Surviving Sepsis Campaign Executive Committee and is a Surviving Sepsis Campaign Guidelines Co-Chair.

Received: 5 January 2018 Accepted: 1 February 2018

Published online: 19 April 2018

\section{References}

1. Dellinger RP, Carlet JM, Masur H et al (2004) Surviving Sepsis Campaign Management Guidelines Committee. Surviving Sepsis Campaign guidelines for management of severe sepsis and septic shock. Crit Care Med 32:858-873

2. Dellinger RP, Carlet JM, Masur H et al (2004) Surviving Sepsis Campaign Management Guidelines Committee. Surviving Sepsis Campaign guidelines for management of severe sepsis and septic shock. Intensive Care Med 30:536-555

3. Dellinger RP, Levy MM, Carlet JM et al (2008) Surviving Sepsis Campaign: international guidelines for management of severe sepsis and septic shock: 2008. Crit Care Med 36:296-327

4. Dellinger RP, Levy MM, Carlet JM et al (2008) Surviving Sepsis Campaign: international guidelines for management of severe sepsis and septic shock: 2008. Intensive Care Med 34:17-60

5. Dellinger RP, Levy MM, Rhodes A et al (2013) Surviving Sepsis Campaign: international guidelines for management of severe sepsis and septic shock, 2012. Intensive Care Med 39:165-228

6. Dellinger RP, Levy MM, Rhodes A et al (2013) Surviving sepsis campaign: international guidelines for management of severe sepsis and septic shock: 2012. Crit Care Med 41:580-637

7. Levy MM, Dellinger RP, Townsend SR et al (2010) Surviving Sepsis Campaign. The Surviving Sepsis Campaign: results of an international guideline-based performance improvement program targeting severe sepsis. Crit Care Med 38:367-374

8. Levy MM, Rhodes A, Phillips GS et al (2015) Surviving Sepsis Campaign: association between performance metrics and outcomes in a 7.5-year study. Crit Care Med 43:3-12

9. Levy MM, Pronovost PJ, Dellinger RP et al (2004) Sepsis change bundles: converting guidelines into meaningful change in behavior and clinical outcome. Crit Care Med 32:S595-\$597

10. Damiani E, Donati A, Serafini G et al (2015) Effect of performance improvement programs on compliance with sepsis bundles and mortality: a systematic review and meta-analysis of observational studies. PLoS One 10:e0125827

11. Rhodes A, Phillips G, Beale R et al (2015) The Surviving Sepsis Campaign bundles and outcome: results from the International Multicentre Prevalence Study on Sepsis (the IMPreSS study). Intensive Care Med 41:1620-1628

12. Rhodes A, Evans L, Alhazzani W et al (2017) Surviving sepsis campaign: international guidelines for management of sepsis and septic shock: 2016. Crit Care Med 45:486-552

13. Rhodes A, Evans L, Alhazzani W et al (2017) Surviving sepsis campaign: International guidelines for management of sepsis and septic shock: 2016. Intensive Care Med 43:304-377

14. http://www.nytimes.com/2012/12/21/nyregion/one-boys-death-movesstate-to-action-to-prevent-others.html. Accessed on 27 December 2017) 
15. https://www.cms.gov/Newsroom/MediaReleaseDatabase/Factsheets/2014-Fact-sheets-items/2014-08-04-2.html. Accessed on 28 December 2017)

16. Seymour CW, Gesten F, Prescott H et al (2017) Time to treatment and mortality during mandated emergency care for sepsis. N Engl J Med 376:2235-2244

17. Liu VX, Morehouse JW, Marelich GP et al (2016) Multicenter implementation of a treatment bundle for patients with sepsis and intermediate lactate values. Am J Respir Crit Care Med 193(11):1264-1270

18. Leisman DE, Doerfler ME, Ward MF et al (2017) Survival benefit and cost savings from compliance with a simplified 3-hour sepsis bundle in a series of prospective, multisite. Observational cohorts. Crit Care Med 45:395-406

19. Ferrer R, Martin-Loeches I, Phillips G et al (2014) Empiric antibiotic treatment reduces mortality in severe sepsis and septic shock from the first hour: results from a guideline-based performance improvement program. Crit Care Med 42:1749-1755

20. Kumar A, Roberts D, Wood KE et al (2006) Duration of hypotension before initiation of effective antimicrobial therapy is the critical determinant of survival in human septic shock. Crit Care Med 34:1589-1596

21. Kumar A (2016) Systematic bias in meta-analyses of time to antimicrobial in sepsis studies. Crit Care Med 44:e234-e235

22. Levy B (2006) Lactate and shock state: the metabolic view. Curr Opin Crit Care 12:315-321

23. Casserly B, Phillips GS, Schorr C et al (2015) Lactate measurements in sepsis-induced tissue hypoperfusion: results from the Surviving Sepsis Campaign database. Crit Care Med 43:567-573

24. Jansen TC, van Bommel J, Schoonderbeek FJ et al (2010) LACTATE study group. Early lactate-guided therapy in intensive care unit patients: a multicenter, open-label, randomized controlled trial. Am J Respir Crit Care Med 182:752-761

25. Jones AE, Shapiro NI, Trzeciak S et al (2010) Emergency Medicine Shock Research Network (EMShockNet) Investigators. Lactate clearance vs central venous oxygen saturation as goals of early sepsis therapy: a randomized clinical trial. JAMA 303:739-746

26. Lyu X, Xu Q, Cai G et al (2015) Efficacies of fluid resuscitation as guided by lactate clearance rate and central venous oxygen saturation in patients with septic shock. Zhonghua Yi Xue Za Zhi 95:496-500

27. Tian HH, Han SS, Lv CJ et al (2012) The effect of early goal lactate clearance rate on the outcome of septic shock patients with severe pneumonia. Zhongguo Wei Zhong Bing Ji Jiu Yi Xue 24:42-45

28. Yu B, Tian HY, Hu ZJ et al (2013) Comparison of the effect of fluid resuscitation as guided either by lactate clearance rate or by central venous oxygen saturation in patients with sepsis. Zhonghua Wei Zhong Bing Ji Jiu Yi Xue 25:578-583

29. Zadroga R, Williams DN, Gottschall R et al (2013) Comparison of 2 blood culture media shows significant differences in bacterial recovery for patients on antimicrobial therapy. Clin Infect Dis 56:790-797

30. Kanegaye JT, Soliemanzadeh P, Bradley JS (2001) Lumbar puncture in pediatric bacterial meningitis: defining the time interval for recovery of cerebrospinal fluid pathogens after parenteral antibiotic pretreatment. Pediatrics 108:1169-1174
31. Cardoso T, Carneiro AH, Ribeiro O et al (2010) Reducing mortality in severe sepsis with the implementation of a core 6-hour bundle: results from the Portuguese community-acquired sepsis study (SACiUCI study). Crit Care 14:R83

32. De Sousa AG, Fernandes Junior CJ, Santos GPD et al (2008) The impact of each action in the Surviving Sepsis Campaign measures on hospital mortality of patients with severe sepsis/septic shock. Einstein 6(3):323-327

33. Acheampong A, Vincent $J$ (2015) A positive fluid balance is an independent prognostic factor in patients with sepsis. Crit Care 19:251

34. Brotfain E, Koyfman L, Toledano R et al (2016) Positive fluid balance as a major predictor of clinical outcome of patients with sepsis/septic shock after ICU discharge. Am J Emerg Med 34:2122-2126

35. Mitchell KH, Carlbom D, Caldwell E et al (2015) Volume overload: prevalence, risk factors, and functional outcome in survivors of septic shock. Ann Am Thorac Soc 12:1837-1844

36. de Oliveira FS, Freitas FG, Ferreira EM et al (2015) Positive fluid balance as a prognostic factor for mortality and acute kidney injury in severe sepsis and septic shock. J Crit Care 30:97-101

37. Malbrain ML, Marik PE, Witters I et al (2014) Fluid overload, de-resuscitation, and outcomes in critically ill or injured patients: a systematic review with suggestions for clinical practice. Anaesthesiol Intensive Ther 46:361-380

38. Day NP, Phu NH, Bethell DP et al (1996) The effects of dopamine and adrenaline infusions on acid-base balance and systemic haemodynamics in severe infection. Lancet 348:219-223

39. De Backer D, Creteur J, Silva E et al (2003) Effects of dopamine, norepinephrine, and epinephrine on the splanchnic circulation in septic shock: which is best? Crit Care Med 31:1659-1667

40. Martin C, Papazian L, Perrin G et al (1993) Norepinephrine or dopamine for the treatment of hyperdynamic septic shock? Chest 103:1826-1831

41. Martin C, Viviand X, Leone M et al (2000) Effect of norepinephrine on the outcome of septic shock. Crit Care Med 28:2758-2765

42. Bollaert PE, Bauer P, Audibert G et al (1990) Effects of epinephrine on hemodynamics and oxygen metabolism in dopamine-resistant septic shock. Chest 98:949-953

43. Levy B, Bollaert PE, Charpentier C et al (1997) Comparison of norepinephrine and dobutamine to epinephrine for hemodynamics, lactate metabolism, and gastric tonometric variables in septic shock: a prospective, randomized study. Intensive Care Med 23:282-287

44. Zhou SX, Qiu HB, Huang YZ et al (2002) Effects of norepinephrine, epinephrine, and norepinephrine-dobutamine on systemic and gastric mucosal oxygenation in septic shock. Acta Pharmacol Sin 23:654-658

45. Mackenzie SJ, Kapadia F, Nimmo GR et al (1991) Adrenaline in treatment of septic shock: effects on haemodynamics and oxygen transport. Intensive Care Med 17:36-39

46. Moran JL, O'Fathartaigh MS, Peisach AR et al (1993) Epinephrine as an inotropic agent in septic shock: a dose-profile analysis. Crit Care Med 21:70-77

47. Yamazaki T, Shimada Y, Taenaka N et al (1982) Circulatory responses to afterloading with phenylephrine in hyperdynamic sepsis. Crit Care Med 10:432-435 